\title{
The Connection between the Distance of the Suppliers and the Keeping of the Safety Stock
}

\author{
Gábor Farkas \\ Széchenyilstván University, Hungary
}

\begin{abstract}
The objective of this research is revealing the connection between the distance of the suppliers and the keeping of the safety stock respectively the provision of the safety times when establishing the logistics strategy of the companies. In this article it will be analyzed when it is worth inserting safety time and when it is justified to holding safety stock so that the base materials, auxiliary materials and parts required for the production can be provided continuously according to the requirements. It will be assumed, that the increase of the distance does not always mean the increase of the transportation time as far as the directions are concerned. In this article, factors that play - besides the distance - a role in the variation of the transportation time are presented. In this research the proportion with which the size of the safety stock and the safety time required for the production when the distance is increasing are defined. Regarding the analyses products with various values, dimensions and needs of utilization are compared. In the final section is determined when it is worth choosing a supplier within a shorter geographic distance and in case of which products it is worth opting for the product that is offered at a lower price but being at a bigger distance.
\end{abstract}

Keywords: transportation, supplier selection, decision support systems, stock piling JEL classification: C10, R4

\section{Introduction}

Focusing the activities on the main business line and outsourcing whatever possible is a tendency among businesses that has started at the end of the 20th century and is still observable. The main benefit of outsourcing is, that the greatest progress possible is achieved by concentrating know-how, for each participant focuses attention on own duties. Flexibility is another advantage offered by outsourcing, for the same product or service is available from several suppliers and so a more diversified product mix can be set up to ensure safe supply any time. Outsourcing also facilitates better capacity utilization, whereas the advantages are clearly manifested in the economy of scale. Thus an increasing number of businesses are getting involved in the production of a product with an extending supply chain. In a long supply chain selecting, monitoring and continuously improving the appropriate stock management strategy is vital, since in an extended supply chain immense stock can pile up with the tying up of capital, furthermore redundant stock cover the imperfect or weak points in the process or may even render swift response to the customers' demands more difficult. The existing literature focuses on the economic order quantity (EOQ), the keeping of the safety stock related to the changing demands, but little attention is given to delivery delay fluctuation and its effects. (Kherbasha et al., 2015) 
The timeliness of this issue rests in the fact that the ever growing diversity of product supply on the market urges the customers to prefer the custom-built or tailored products and services in a very short lead time. Color is an essential element of the product line. The wider selection is offered in color the more parts we need to have on stock, moreover, fast and flexible response to the customers' ever changing demands also requires stockpiling in the supply chain. (Cenigaa et al., 2015)

The goal of this research is to reveal the interrelations that may exist between transport distances and the stocking strategy as well as to examine the possibilities of stock decrease in the supply chain. In the first section a review is presented regarding the existing stocking strategies. In the second part of this article the methods are described, which were used in the analysis. The methodology is followed by the details of the analysis. The article is closed with the discussion and conclusions of the research.

\section{Model of Stocking Strategy}

In supply chain, stocking or stockpiling is to ensure uninterrupted material supply and deliveries to customers even amidst both quantitative and timely fluctuation in demand and supply. The cost conflict of stocking rests in that the higher the standard of service is the higher the inventory costs grow consequently product prices will grow. Finding the balance is crucial between the stocking costs and the standard of deliveries or services provided to customers. (Lin et al., 2016)

The figure below illustrates the function of stock development and time. The section marked with Tp is the time for replenishment that is the period between placing the order for supply and the delivery of the incoming goods.

Figure 1

Function of stock level and time

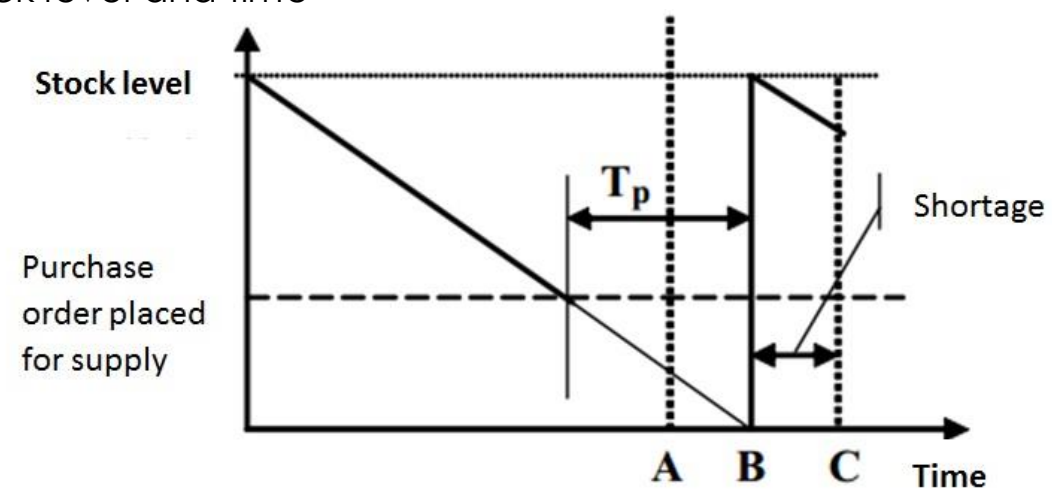

Source: Rushton, A., Croucher, P., Baker, P. (2006), The Handbook of Logistics and Distribution Management, Kogan Page, London

A stocking model with constant time period and variable lot size is demonstrated in the figure above. Point B marks the time when the ordered items arrive on time and the stock is also shrinking in the scheduled pace. However it rarely occurs in real life. Exhaustion of the stock may be faster depending on the customer orders placed (Point A), or slower (Point $C$ ), and even the transport time, due to unexpected events, may be shorter (Point A), or longer (Point C). Possibilities are gathered in the table below: 
Table 1

Demonstration of Relationship between Region and Business Performance

\begin{tabular}{llll}
\hline & $T_{A}$ & $T_{B}$ & TC \\
$S_{A}$ & OPT & NOK & NOK \\
$S_{B}$ & OK & OPT & NOK \\
$S_{C}$ & OK & OK & OPT \\
\hline
\end{tabular}

Source: Author's illustration

Optimal cases are marked in the table with OPT - when the replenishment supply is received in time when stocks have run out. When the delivery arrives earlier it is acceptable, so OK is used for marking, but note that this may also cause difficulties in sticking or even piling up in the receipt of incoming goods. When the stock runs out earlier than the supply is received, it is unacceptable, so NOK (not OK) is used for marking.

Shortages are not acceptable, whereas:

- orders received in the course of the shortage may be lost

- customers may be lost in the future

- appreciation and reputation of the company may get impaired

- downtime - involving staff and machinery alike

- costs are incurred for extraordinary actions are needed to avoid or diminish losses

Shortages can be compensated either by safety stock or stock reserve and/or time reserve. Optimizing is primarily not for determining the inventory costs or the optimum of the costs of shortage, but for achieving an adequate servicing standard at the possibly lowest cost. (Jean et al., 2015)

\section{Methodology}

In this research I intend to direct the focus of attention to the unexpected changes in supply time. The stock reserve size is considered as given due to the varying demands and I examine to what extent the uncertainty due to fluctuating supply time affects the standard of services rendered. Additionally, it is presumed, that adequate goods are received in sufficient quantities and quality at the appropriate place. Supposing normal distribution the uncertainty of supply is described as follows:

Figure 2

Unexpected fluctuation in the supplies

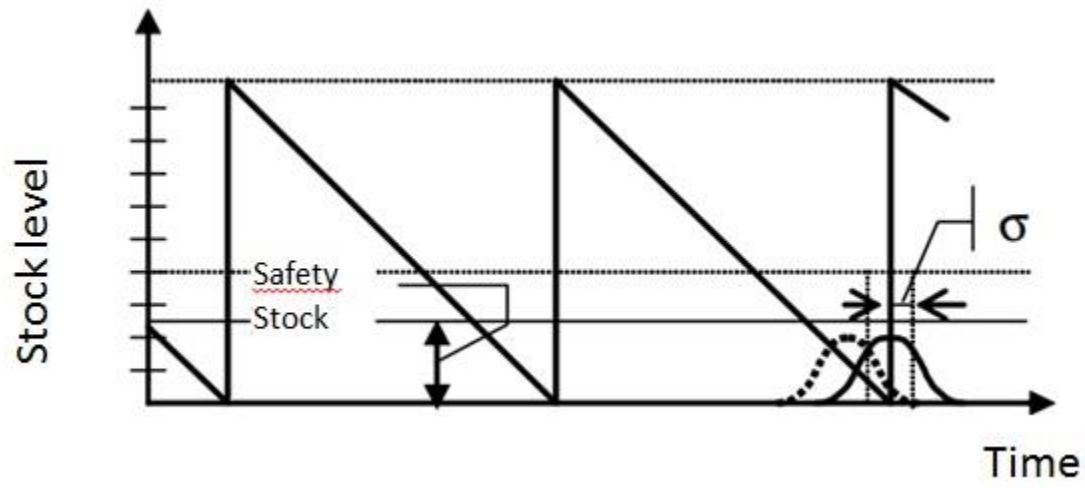

Source: Rushton, A., Croucher, P., Baker, P.(2006), The Handbook of Logistics and Distribution Management, KoganPage, London 
Parts purchased by a large Hungarian company were examined. No difference was made regarding the value, size, weight and the ordered quantity of the parts purchased, for the purpose of this survey was to reveal uncertainties in the arrival of supply. Each of the parts involved in this survey was forwarded as part-load, and each freight forwarder was selected by the company involved in this study. The ever changing quantity and the time of arrival considering the orders render this survey more difficult. To eliminate the effect of this factor on the results, the differences in the ordered quantity of parts and the quantity of actually supplied parts was not taken into account, and the difference between the requested date of delivery and the date of actual arrival was measured but the difference between the notification date and the date of arrival as scheduled were examined.

Survey steps:

- Select 9 parts, supplied by 9 different suppliers from different geographical locations

- list of arrivals considering the selected parts for 1 year retroactively (date of delivery note, date of booking)

- assign scheduled delivery dates to the delivery note dates considering also the business days

- calculate the difference $\left(T_{d}\right)$ between the date of actual arrival $\left(T_{a}\right)$ and the sending date $\left(\mathrm{T}_{\mathrm{s}}\right)$ of arrival

- analysis of the deviation of the Lead Time (TLT)

$$
T_{d}=\left(T_{a}-T_{s}\right)-T_{L T}
$$

\section{Results}

The result of the analysis is demonstrated in Table 2. The first column of the table contains the countries - it means the depot of the supplier. Lead time is the calculated transport time agreed with the carriers. In time deliveries column shows the rate of punctuality. The delay distribution is calculated in the fourth column. The last column contains the biggest delays.

Table 2

The results are included in the following table

\begin{tabular}{|c|c|c|c|c|}
\hline Country & Lead Time & In time deliveries & $\begin{array}{l}\text { Delay } \\
\text { distribution }\end{array}$ & $\begin{array}{l}\text { Biggest } \\
\text { difference }\end{array}$ \\
\hline Hungary (250 km) & 1 day & $75 \%$ & 0,59 & 2 days \\
\hline Austria $(450 \mathrm{~km})$ & 1 day & $15 \%$ & 1,45 & 2 days \\
\hline $\begin{array}{l}\text { Germany } \\
\text { Roadway } \\
\text { km) }\end{array}$ & 3 days & $43 \%$ & 1,35 & 4 days \\
\hline $\begin{array}{l}\text { Germany } \\
\text { Intermodal } \quad(1000 \\
\text { km) }\end{array}$ & 2 days & $41 \%$ & 1,05 & 4 days \\
\hline $\begin{array}{l}\text { Romania } \quad(1000 \\
\text { km) }\end{array}$ & 3 days & $31 \%$ & 1,81 & 5 days \\
\hline $\begin{array}{l}\text { Bulgaria } \quad(1150 \\
\text { km) }\end{array}$ & 3 days & $64 \%$ & 0,77 & 2 days \\
\hline Turkey (1700 km) & 6 days & $24 \%$ & 2,27 & 9 days \\
\hline $\begin{array}{l}\text { China - Air (15000 } \\
\text { km) }\end{array}$ & 7 & $20 \%$ & 3,29 & 8 days \\
\hline $\begin{array}{l}\text { China - Ship } \\
(15000 \mathrm{~km})\end{array}$ & 42 days & $0 \%$ & 7,51 & 31 days \\
\hline
\end{tabular}


The target-diagram below is visualizing the fluctuation of the delivery delays. Delays occur more times, than too early deliveries. The smallest distance is in case of the Hungarian supplier and it means the biggest punctuality and smallest delay risk. The punctuality is not good in case of the Austrian supplier, because of too early deliveries, but as far as the risk is concerned, Austria is very favorable. Bulgaria has also good results. In case of China, the delivery date is unpredictable; the biggest delay is 31 days. To ensure safe supply any time, we must use bigger safety time in case of goods from Chinese suppliers. Based on the dates of this research 31 days safety time is needed to ensure $100 \%$ supply. It also means that in case of in time delivery, the shipment must be stored 31 days. On this base, I suggest to supply goods from China, which are small-sized, cheap and self-colored. Otherwise it might be better to reduce the distance of the supplier.

Figure 3

Distribution of delivery delay fluctuation

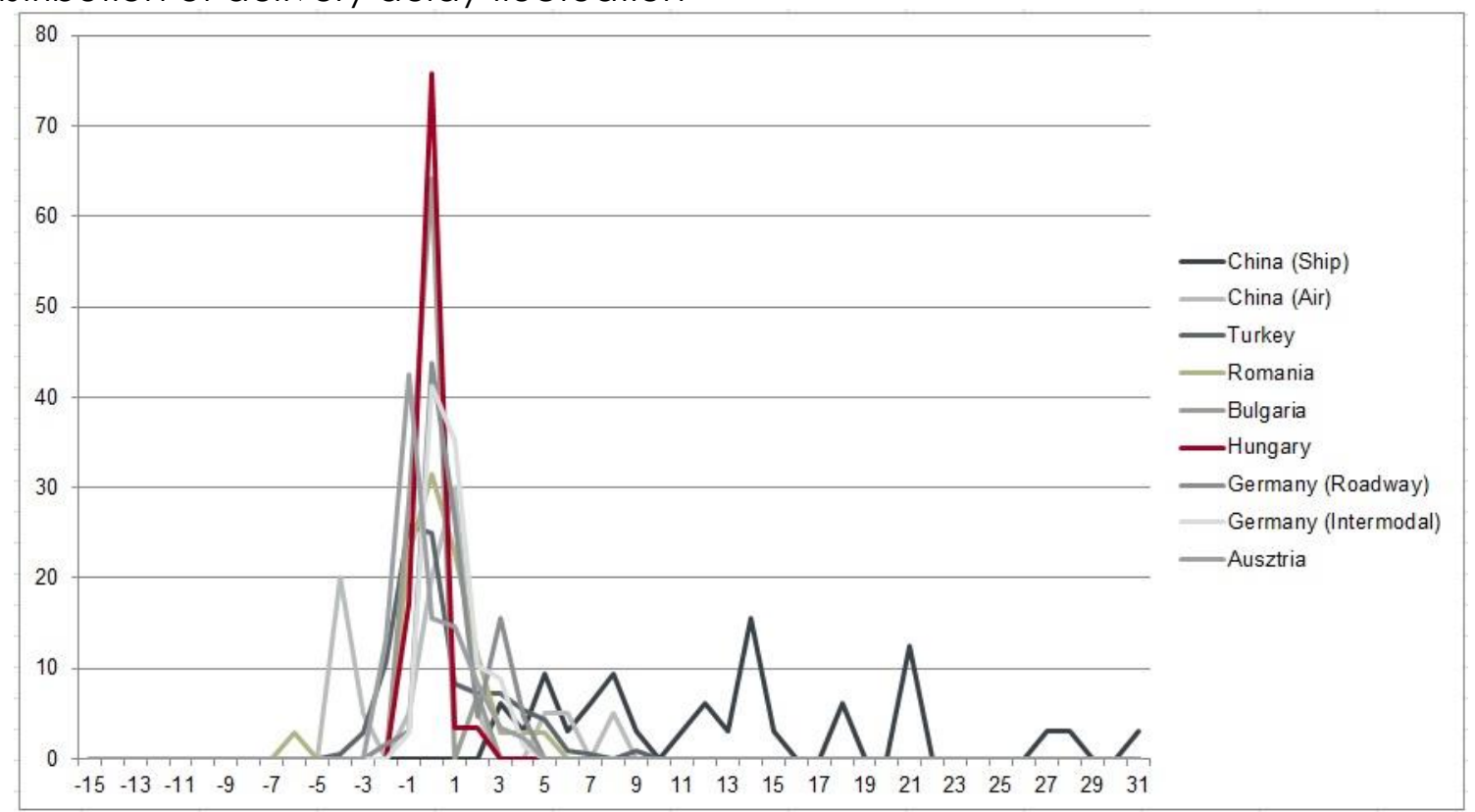

Source: Author's illustration

\section{Discussion}

The survey shows that the lead-time fluctuation regarding incoming supplies has followed the normal distribution. Early deliveries are a bit rarer than late deliveries. As it was expected, by increasing the distances the uncertainty of in-time deliveries grows, however, this applies only in the EU, as regards the supplies from Turkey there is a surge, while in the case of supplies from the overseas the deviation even exceeds the cycle time of orders (weekly scheduling). Based on the foregoing it may be stated that uncertainty as to the arrival of supplies depends not merely on distances but also on the peculiarities of transportation, the number of occasions transfer or transshipment of goods is needed, geographical features and even on customs clearance procedures.

\section{Conclusion}

To avoid shortages in parts supply due to delayed deliveries safety stock level can be increased or reserve time (or time margin) may also be applied when placing orders, i.e. the scheduled date of delivery is brought forth in time (earlier delivery 
date is specified) compared to the scheduled date of use to meet the required standard of service. However, it is not practical to further increase the safety stock level for in cases when the demand for a part drops for longer or shorter periods, the stock of this part may become redundant. A disadvantage of applying time reserve or time margin is that order periods become longer therefore estimation or forecasts regarding the next order placement time will be inaccurate and inventory costs will increase whereas in the case described above the parts from the Chinese supplier arrived one week earlier than scheduled for use. In the case of overseas supplies, constant order periods are applied, in the examined case orders are placed on a weekly basis, that is 6-weeks stock is on road, but this also entails tying up of capital. This research reveals the connection between the distance of the suppliers and the risk of delays, but it does not contain solutions if a delay occurs. It would be necessitous to analyze this possible emergency cases and to develop a strategy.

\section{References}

1. Cenigaa P., Sukalovab V. (2015), "Future of Logistics Management in the Process of Globalization", Procedia Economics and Finance, Vol. 26, pp. 160 - 166.

2. Daniälle, B., Nijkamp P. (1999), "Globalization, transport and the environment: new perspectives for ecological economics", Ecological Economics, Vol. 31, pp. 331-346.

3. Ghodsypour, S.H., O'Brien, C. (2001), "The total cost of logistics in supplier selection, under conditions of multiple sourcing, multiple criteria and capacity constraint", Int. J. Production Economics, Vol. 73, pp. 15-27.

4. Heydari, J., Mahmoodi M., Taleizadeh, A. (2016), "Lead time aggregation: A threeechelon supply chain model", Transportation Research Part E, Vol. 89, pp. 215-233.

5. Jian, M., Fang, X., Jin, L. (2015) - "The impact of lead time compression on demand forecasting risk and production cost: A newsvendor model", Transportation Research Part E, Vol. 84, pp. 61-72.

6. Kherbasha, O., Mocana, M., L. (2015), "A Review of Logistics and Transport Sector as a Factor of Globalization", Procedia Economics and Finance, Vol. 27, pp. 42 - 47.

7. Lin, H. S. (2016), "Investing in lead-time variability reduction in a collaborative Vendor buyer supply chain model with stochastic lead time", Computer \& Operations Research, Vol. 72, pp. 43-49.

8. Miozzo, M., Dewick, P., Green, K. (2005), "Globalization and the environment: the long-term effects of technology on the international division of labor and energy demand", Manchester School of Management, UMIST, University of Manchester, P.O. Box 88, Manchester M60 1QD, UK Futures, Vol. 37, pp. 521-546.

9. Rushton, A., Croucher, P., Baker, P. (2006), The Handbook of Logistics and Distribution Management, KoganPage, London

10. Wu, D., Olson, L.D. (2008), "Supply chain risk, simulation, and vendor selection", Int. J. Production Economics, Vol. 114, pp. 646- 655.

11. Zhang, J., Zhang, M. (2011), "Supplier selection and purchase problem with fixed cost and constrained order quantities under stochastic demand", Int. J. Production Economics, Vol. 129, pp. 1-7.

\section{About the author}

Gábor Farkas is currently a Ph.D. student in the Department of Logistics and Forwarding at Széchenyilstván University, Hungary. His research interests include supply chain management, supplier selection and evaluation problems. The author can be contacted at farkas.gabor@sze.hu. 